\title{
Pengembangan Desain Treadmill Sebagai Alat Latihan Berjalan Pada Cerebral Palsy dengan Memanfaatkan Realitas Virtual
}

\author{
Irma Mayla Andreani dan Djoko Kuswanto \\ Departemen Desain Produk, Fakultas Arsitektur Desain Dan Perencanaan, \\ Institut Teknologi Sepuluh Nopember (ITS) \\ e-mail:crewol@prodes.its.ac.id
}

\begin{abstract}
Abstrak-Cerebral Palsy (CP) adalah suatu kelainan statis nonprogresif yang disebabkan oleh cedera otak pada periode prenatal, perinatal dan postural. Kelainan ini mempengaruhi ketidakmampuan penderita untuk mengendalikan fungsi motorik, postur/sikap dan pergerakan akibat kerusakan sistem saraf pusat. Belum ada pengobatan yang mampu mengobati kelainan ini. Namun, terdapat beberapa metode yang bisa digunakan untuk melatih fungsi gerak penderita berdasarkan potensi dan kemampuan mereka, salah satunya adalah latihan fungsi gerak motorik kasar, khususnya untuk latihan berjalan. Latihan berjalan membutuhkan ruang gerak yang cukup luas dengan pengawasan dari beberapa orang terapis karena apabila terjatuh, dikhawatirkan akan terjadi cedera pada bagian otot kaki. Selain itu, suasana ruang terapi sangat mempengaruhi psikis penderita $C P$ sehingga tak sedikit kasus penderita yang berpindah tempat terapi demi untuk mencari suasana terapi yang berbeda. Tujuan dari perancangan ini adalah untuk menciptakan alat latihan berjalan yang lebih aman, dapat diawasi dengan mudah serta memberikan suasana latihan yang menyenangkan. Proses desain dimulai dengan pengumpulan data melalui metode komparasi jurnal, observasi dan pendekatan terhadap stakeholder. Melalui pengumpulan data tersebut didapatkan permasalahan dan kebutuhan penderita $C P$ dalam melakukan latihan berjalan yang kemudian diolah bersama dengan literatur yang berkaitan sehingga menjadi produk dengan konsep desain stability dan fun. Hasil perancangan ini berupa alat latihan berjalan berupa Treadmill yang dilengkapi dengan safety belt dan memanfaatkan lingkungan virtual sebagai pengganti suasana ruangan latihan yang dapat dijelajahi oleh penderita.
\end{abstract}

Kata Kunci-Cerebral Palsy, Realitas Virtual, Treadmill.

\section{PENDAHULUAN}

C EREBRAL Palsy (CP) adalah suatu kelainan statis nonprogresif yang disebabkan oleh cedera otak pada periode prenatal, perinatal dan postural, yang berpengaruh pada ketidakmampuan untuk mengendalikan fungsi motorik, postur/sikap dan pergerakan akibat kerusakan sistem saraf pusat [1]. Untuk di Indonesia, kurang lebih 5,5 per 1000 dengan rasio penyeimbangan yang sama dalam aspek jenis kelamin, ras dan Negara [2]. Untuk mengetahui kemampuan motorik kasar $\mathrm{CP}$, dilakukan pengajian secara internasional yang biasa disebut sebagai Gross Motor Function Classification System (GMFCS) [3]. GMFCS dibagi atas 5 level, yaitu:

1. Level I : Aktivitas tidak terbatas, keseimbangan masih kurang baik

2. Level II : Ada sedikit keterbatasan dalam aktivitas
3. Level III : Berjalan dengan menggunakan alat bantu

4. Level IV : Perpindahan mandiri menggunakan kursi roda dengan keterbatasan

5. Level V : Perpindahan menggunakan kursi roda dengan bantuan dari orang lain

$C P$ tidak dapat disembuhkan namun pengobatan dan terapi dapat meningkatkan kemampuan penderita [4]. Sebagian besar penderita CP memiliki kemungkinan untuk berjalan $60 \%$ dengan alat bantu, $10 \%$ berjalan dengan alat bantu, 30\% menggunakan kursi roda atau alat bantu [5]. Namun tanpa latihan dan rehabilitasi medis, penderita CP dapat mengalami penurunan kemampuan fisik. Rehabilitasi saat ini terbagi atas 2 tipe, yaitu rehabilitasi konvensional dan teknologi rehabilitasi. Rehabilitasi konvensional mulai ditinggalkan karena suasananya cenderung menimbulkan rasa tertekan sehingga mengakibatkan trauma. Hal ini mendasari perkembangan teknologi rehabilitasi untuk mengkombinasikan rehailitasi konvensional dengan penambahan teknologi untuk menciptakan ketertarikan pada anak selama proses rehabilitasi. Meskipun demikian, di Indonesia belum ada pusat rehabilitasi yang menggunakan teknologi. Ini dikarenakan keraguan terapis terhadap desain dan penggunaan kacamata realitas virtual yang kurang aman dan belum bisa memenuhi standar untuk digunakan pada CP. Dibalik kekhawatiran itu, telah banyak penelitian yang menunjukkan bahwa penggunaan realitas virtual dapat menjanjikan teknologi rehabilitasi yang lebih baik [6],[7],[8], [9], dan [10].

Berdasarkan data assesment YPAC Surabaya, pada tahun ajaran 2015-2016 terdaftar 73 penderita binaan dengan kasus $\mathrm{CP}$ dengan jenis terbanyak adalah jenis campuran antara spastik dan atetoid pada usia TK hingga sekolah dasar [11]. Usia tersebut adalah usia tumbuh kembang dimana penderita senang bermain dan hal ini berpotensi besar untuk dikembangkan di Indonesia. Dengan memanfaatkan literatur dan informasi yang ada baik dari dalam maupun luar negeri, penulis akan merancang alat untuk latihan berjalan berupa treadmill yang akan dikombinasikan penggunaannya dengan realitas virtual untuk menarik minat penderita $\mathrm{CP}$ dalam berjalan menjelajahi lingkungan tersebut. 
Tabel 2.

Komparasi literatur jurnal mengenai teknologi permainan

\begin{tabular}{|c|c|c|c|c|}
\hline $\begin{array}{l}\text { Paramet } \\
\text { er }\end{array}$ & $\begin{array}{l}\text { Designing } \\
\text { Toys and } \\
\text { Technologi } \\
\text { es for } \\
\text { Rehabi- } \\
\text { litation } \\
{[12]}\end{array}$ & $\begin{array}{l}\text { Comple- } \\
\text { mentary } \\
\text { Treatment for } \\
\text { Children CP } \\
\text { based Virtual } \\
\text { Reality [13] }\end{array}$ & $\begin{array}{l}\text { Virtual Reality } \\
\text { Technology for } \\
\text { Rehabilitation } \\
\text { of CP : A } \\
\text { Literature } \\
\text { Review [14] }\end{array}$ & $\begin{array}{l}\text { BiMU- Inertial } \\
\text { sensors and } \\
\text { Virtual Reality } \\
\text { Games for The } \\
\text { Rehabilita-tion } \\
\text { of the Upper } \\
\text { Limb in CP } \\
\text { [15] }\end{array}$ \\
\hline Subjek & $\begin{array}{l}\text { Psikologi } \\
\text { anak dan } \\
\text { produk } \\
\text { inovasi }\end{array}$ & $\begin{array}{l}\text { Ling-kungan } \\
\text { virtual }\end{array}$ & $\begin{array}{l}\text { Literature } \\
\text { teknologi } \\
\text { untuk } \\
\text { rehabilita-si }\end{array}$ & Platform BiMU \\
\hline Objek & $\begin{array}{l}\text { Mainan } \\
\text { interak-tif }\end{array}$ & $\begin{array}{l}\text { Rehabilitasi } \\
\text { kognitif dan } \\
\text { motorik }\end{array}$ & $\begin{array}{l}\text { Tingkat } \\
\text { keberhasilan } \\
\text { terapi dengan } \\
\text { teknologi }\end{array}$ & $\begin{array}{l}\text { Penamba-han } \\
\text { sensor dan } \\
\text { game Virtual } \\
\text { Reality }\end{array}$ \\
\hline Tujuan & $\begin{array}{l}\text { Mende- } \\
\text { sain, } \\
\text { mengem- } \\
\text { bangkan, } \\
\text { menge- } \\
\text { valuasi } \\
\text { mainan } \\
\text { terapi }\end{array}$ & $\begin{array}{l}\text { Mendo-rong } \\
\text { kemampuan } \\
\text { kognitif dan } \\
\text { motorik anak }\end{array}$ & $\begin{array}{l}\text { Menentukan } \\
\text { teknologi } \\
\text { yang paling } \\
\text { efektif }\end{array}$ & $\begin{array}{l}\text { Mengapli- } \\
\text { kasikan Virtual } \\
\text { Reality }\end{array}$ \\
\hline $\begin{array}{l}\text { Teknolo } \\
\text { gi }\end{array}$ & $\begin{array}{l}\text { Sensor } \\
\text { morotik }\end{array}$ & $\begin{array}{l}\text { Virtual } \\
\text { Reality, } \\
\text { sensor Leap } \\
\text { Motion dan } \\
\text { sensor Mind- } \\
\text { wave }\end{array}$ & $\begin{array}{l}\text { Virtual } \\
\text { Reality, } \\
\text { Augmen-ted } \\
\text { Reality, } \\
\text { Nintendo } \\
\text { Wii, The } \\
\text { sensor Kinect }\end{array}$ & $\begin{array}{l}\text { Sensor inersial } \\
\text { (WIMU) dan } \\
\text { permainan } \\
\text { Virtual Reality }\end{array}$ \\
\hline $\begin{array}{l}\text { Dampak } \\
\text { Umum }\end{array}$ & $\begin{array}{l}\text { Mampu } \\
\text { melaku- } \\
\text { kan } \\
\text { gerakan } \\
\text { yang sulit }\end{array}$ & $\begin{array}{l}\text { Mendapat- } \\
\text { kan } \\
\text { kemajuan } \\
\text { kognitif dan } \\
\text { motorik }\end{array}$ & $\begin{array}{l}\text { Virtual } \\
\text { Reality yang } \\
\text { paling efektif }\end{array}$ & $\begin{array}{l}\text { Kemajuan } \\
\text { signifikan } \\
\text { dalam motorik } \\
\text { pasien }\end{array}$ \\
\hline $\begin{array}{l}\text { Dampak } \\
\text { Psikolog } \\
\text { i }\end{array}$ & $\begin{array}{l}\text { Lebih } \\
\text { berse- } \\
\text { mangat } \\
\text { menja- } \\
\text { lankan } \\
\text { terapi }\end{array}$ & $\begin{array}{l}\text { Lebih } \\
\text { bersemangat } \\
\text { menjalani } \\
\text { terapi }\end{array}$ & $\begin{array}{l}\text { Lebih fokus } \\
\text { dalam } \\
\text { mengem- } \\
\text { bangkan } \\
\text { teknologi } \\
\text { rehabilitasi }\end{array}$ & $\begin{array}{l}\text { Pasien } \\
\text { mengalami } \\
\text { kemajuan dan } \\
\text { peneliti optimis }\end{array}$ \\
\hline
\end{tabular}

\section{II.URAIAN PENELITIAN}

\section{A. Komparasi Literatur}

Komparasi literatur adalah perbandingan beberapa penelitian yang telah ditinjau dan dipelajari dengan tujuan tertentu. Metode ini bertujuan untuk menemukan sebuah faktor penelitian yang dapat menjadi acuan bagi penelitian. Diawali dengan mengumpulkan literatur dengan penelitian sejenis, yang kemudian dikaji ulang dengan menggunakan parameter penelitian yang dibutuhkan.

\section{B. Survey Lapangan Dan Wawancara}

Survey lapangan adalah metode yang dilakukan untuk mengetahui kebutuhan berdasarkan situasi dan kondisi yang dialami oleh stakeholder, baik itu oleh user, orangtua user, terapis maupun pemilik yayasan. Selain melalui survey, juga dibutuhkan wawancara yang mendalam untuk mengetahui kebutuhan user berdasarkan keluhan serta pengamatan langsung saat user melakukan rehabilitasi.

\section{Studi dan Analisa}

Studi dan analisis dilakukan berdasarkan kebutuhan penelitian untuk mengetahui kebutuhan user, fitur yang dibutuhkan, mekanik yang digunakan serta dimensi produk. Studi dilakukan dengan membandingkan 2 atau lebih literatur untuk mengetahui mana yang lebih tepat digunakan
Tabel 1.

Analisis kebutuhan berdasarkan level GMFCS

\begin{tabular}{|c|c|c|c|}
\hline $\begin{array}{l}\text { Data } \\
\text { Jurnal }\end{array}$ & $\begin{array}{l}\text { Level I } \\
\text { Dalam Ruangan : } \\
\text { Menggunakan alat } \\
\text { bantu untuk } \\
\text { keamanan } \\
\text { Tangga : Menaiki } \\
\text { tangga dengan } \\
\text { berpengangan } \\
\text { pada hand rails } \\
\text { Luar Ruangan : } \\
\text { Menggunakan } \\
\text { kursi roda }\end{array}$ & $\begin{array}{l}\text { Level II } \\
\text { Dalam Ruangan : } \\
\text { Menggunakan alat } \\
\text { bantu gerak } \\
\text { Sekolah : } \\
\text { Menggunakan kursi } \\
\text { roda manual atau } \\
\text { listrik } \\
\text { Tangga : Menaiki } \\
\text { tangga dengan } \\
\text { berpegang pada hand } \\
\text { rails dengan bantuan } \\
\text { asisten } \\
\text { Luar Ruangan : } \\
\text { Menggunakan kursi } \\
\text { roda }\end{array}$ & $\begin{array}{l}\text { Level III } \\
\text { Dalam } \\
\text { Ruangan : } \\
\text { Berjalan jarak } \\
\text { pendek dengan } \\
\text { bantuan asisten, } \\
\text { alat bantu jalan } \\
\text { beroda atau } \\
\text { penyangga badan } \\
\text { untuk berjalan } \\
\text { Tangga : bisa } \\
\text { dengan bantuan } \\
\text { asisten dan tetap } \\
\text { berpengangan } \\
\text { pada handrail di } \\
\text { samping kiri dan } \\
\text { kanan tangga } \\
\text { Luar Ruangan: } \\
\text { Menggunakan } \\
\text { kursi roda } \\
\text { dengan bantuan } \\
\text { asisten atau } \\
\text { menggunakan } \\
\text { kursi roda } \\
\text { elektrik }\end{array}$ \\
\hline $\begin{array}{l}\text { Postur } \\
\text { dan } \\
\text { gesture }\end{array}$ & & & \\
\hline Posture & $\begin{array}{l}\text { Gambar } 1 \text { siluet } \\
\text { GMFCS level } 2 \\
\text { (warna oranye } \\
\text { adalah bagian otot } \\
\text { yang digunakan) }\end{array}$ & $\begin{array}{c}\text { Gambar } 2 \text { siluet } \\
\text { GMFCS level II } \\
\text { (warna abu-abu } \\
\text { sebagai asisten } \\
\text { latihan jalan dan } \\
\text { warna oranye adalah } \\
\text { otot yang digunakan) } \\
\text { Level II }\end{array}$ & $\begin{array}{c}\text { Gambar } 3 \text { siluet } \\
\text { GMFCS level III } \\
\text { ( abu-abu } \\
\text { sebagai asisten } \\
\text { latihan dan } \\
\text { oranye adalah } \\
\text { otot yang } \\
\text { digunakan) } \\
\text { Level III }\end{array}$ \\
\hline
\end{tabular}

dan

Gesture

Penentuan otot

kontraksi

diasumsikan

dengan otot postur

normal pada saat

berjalan.

Referensi :

www.cadarn.ac.uk

Solusi

Handle agar lebih

seimbang

Penghalang

diantara kedua

kaki agar tidak

menyilang di

bagian lutut

kebawah (apabila

terdapat scissor

gait)
Penentuan otot

kontraksi

diasumsikan dengan

otot postur normal

pada saat berjalan.

Referensi :

www.cadarn.ac.uk

Handle untuk pegangan agar lebih seimbang

Penjaga postur

hingga bagian

lumbar yang

mengikat ke bagian

posterior (apabila

postur tubuh tidak

normal dan tidak ada

kontraktur sendi)
Penentuan otot

kontraksi

melalui

wawancara pada anak CP berusia

8 tahun dengan

pengaruh

orangtua

hingga bagian

ketiak

Penyokong

diantara kedua

selangkang

karena belum

bisa berdiri

sendiri
Penjaga postur 
sebagai acuan pustaka. Analisis diawali dengan studi literatur yang kemudian diuji coba untuk dapat mendapatkan hasil yang dapat diaplikasikan pada produk. Analisis bisa dilakukan baik dengan uji coba secara langsung maupun dengan bantu software digital.

\section{HASIL DAN PEMBAHASAN}

\section{A. Komparasi Literatur}

Kesimpulan dari hasil komparasi literatur pada Tabel 1 adalah banyak peneliti yang telah melakukan penelitian mengenai teknologi yang tepat untuk rehabilitasi pada $C P$ dan dari sejumlah penelitian yang telah di review, menunjukkan bahwa teknologi dengan menggunakan Virtual Reality atau Virtual Environment memberikan dampak yang paling menjanjikan jika dibandingkan dengan teknologi yang lain.

\section{B. Studi Dan Analisis}

Pada klasifikasi penderita CP dengan Gross Motor Function Classification System, penderita CP dibagi menjadi 5 level dengan keterangan alat bantu jalan yang digunakan berdasarkan pada kemampuan jalan anak dalam kehidupan sehari-hari. Dalam analisis ini, akan dijabarkan kebutuhan dan kondisi fisik pada level I hingga III GMFCS sehingga dapat ditentukan fitur apa yang dibutuhkan untuk setiap level. (Tabel 2)

Berdasarkan dari hasil analisa diatas, maka didapatkan fitur-fitur yang dibutuhkan untuk memperbaiki postur tubuh serta kebutuhan gestur jalan penderita berupa handle, penghalang antara kedua kaki(yang biasa disebut sebagai abduction board), penjaga postur spinal dalam bentuk sandaran, serta penyokong berat badan pada titik tumpu badan apabila pengguna merasa lelah saat berjalannya proses terapi. Kemudian dilakukan studi postur untuk mengetahui bentuk komponen pendukung fitur yang dibutuhkan sehingga dapat sekaligus memnuhi unsur ergonomic dari pengguna.

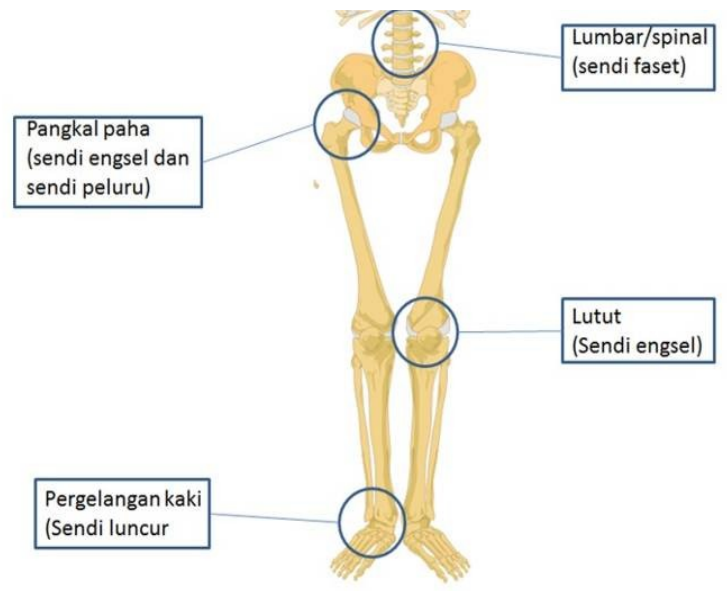

Gambar 4. Sendi yang perlu diperhatikan pada kaki.

Kekakuan otot yang dialami oleh penderita $C P$ berpengaruh pada postur tubuh penderita, terutama pada bagian tulang punggung serta postur kaki sehingga dibutuhkan adanya perhatian khusus untuk perbaikan postur tubuh serta postur kaki. Perbedaan postur ini terfokus pada beberapa titik sendi, khususnya pada sendi yang ada pada tiap ruas tulang belakang dan kaki yang termasuk didalamnya pangkal paha, lutut serta tumit.

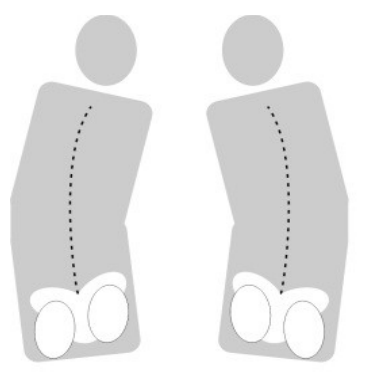

Gambar 5. Perubahan postur tubuh.
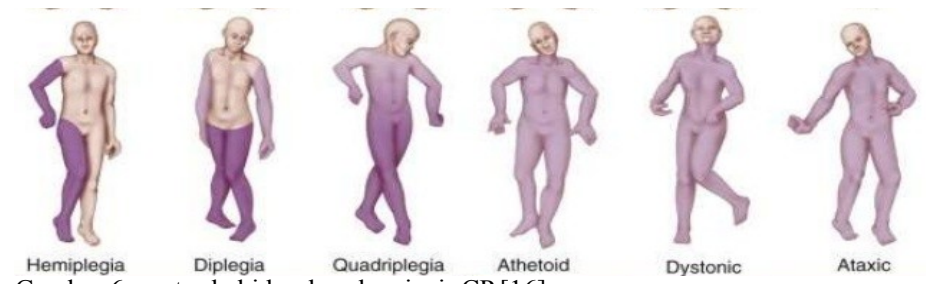

Gambar 6. postur kaki berdasarkan jenis CP [16]

Tabel 3.

Rekomendasi garis bentukan untuk pengaman

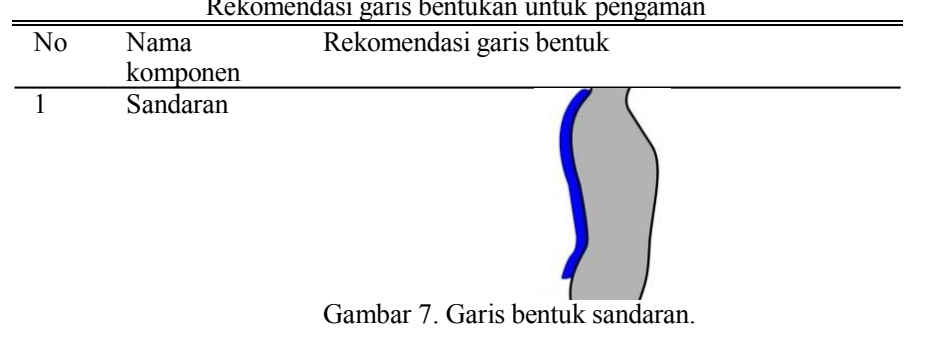

2 Penyokong pinggang

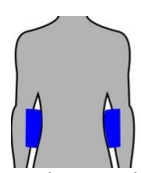

Gambar 9. Garis bentuk penyokong pinggang.
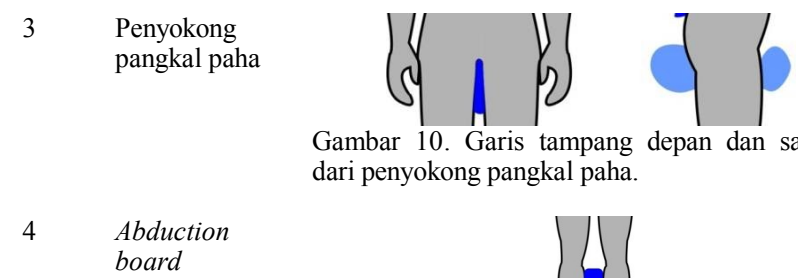

Gambar 10. Garis tampang depan dan samping dari penyokong pangkal paha.

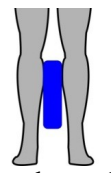

Gambar 11. Garis bentuk penghalang antara kedua kaki.

Adanya perubahan postur kaki dan postur tubuh tersebut menunjukkan adanya kebutuhan attribut tambahan untuk perbaikan postur tubuh dan kaki dengan bentuk yang disesuaikan dengan kondisi kaki normal dan kondisi tulang spinal pada umumnya. Untuk itu dibutuhkan adanya sandaran yang menyesuaikan bentuk normal dari spinal serta pengaman yang membuat tubuh menempel pada sandaran, penyokong bagian pinggang untuk perbaikan postur, dudukan untuk membuka pangkal paha yang menyempit dan penghalang diantara kedua kaki penderita agar kaki tidak menyilang ataupun menempel pada bagian betis. 
Rekomendasi yang dihasilkan yaitu pengaman tambahan yang menahan tubuh menempel pada sandaran akan diberi garis bentukan sesuai dengan postur tubuh normal yang diberikan akan diterjemahkan dalam gambar sebagai acuan bentuk dari komponen produk sehingga badan akan cenderung untuk mengikuti postur tubuh normal manusia pada umumnya.

Analisis diatas menjadi rujukan untuk bentukan pendukung postur tubuh serta fitur yang dibutuhkan pada treadmill. Untuk ukurannya akan disesuaikan dengan antropometri manusia pada umumnya karena untuk antropometri dari penderita $\mathrm{CP}$ sulit untuk dapat terukur dengan benar. Sehingga proses pengolahan data ini akan memunculkan alternatif desain sesuai dengan kriteria dari hasil studi dan analisis yang telah dilakukan.

\section{C.Alternatif Desain}

Hasil komparasi literatur serta studi dan analisis menghasilkan persyaratan desain yang kemudian diimplemntasikan ke dalam beberapa alternatif desain treadmill sehingga desain dapat memenuhi kebutuhan pengguna dalam latihan berjalan sesuai dengan level kemampuan GMFCS penderita CP.

1. Alternatif desain 1

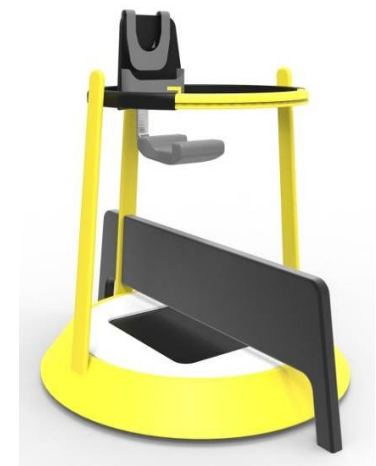

Gambar 12. Alternatif desain 1.

Alternatif desain yang pertama dilengkapi dengan dudukan dengan bentuk cekungan bagian tengah, dengan sandaran dan belt yang mengikuti garis yang telah direkomendasikan. Pada gambar ini abduction board dipasang untuk mengetahui seberapa tinggi saat ada di treadmill serta perbandingan dengan tiang penyangga pegangan dan pengamannya.

\section{Alternatif desain 2}

Alternatif kedua memiliki kelengkapan yang sama dengan alternatif desain yang pertama yaitu pengaman dan dudukan sesuai rekomendasi dari hasil studi dan analisis. Namun, ada perbedaan pada bagian tiang penyangga untuk pegangan dan pengaman yang ada.

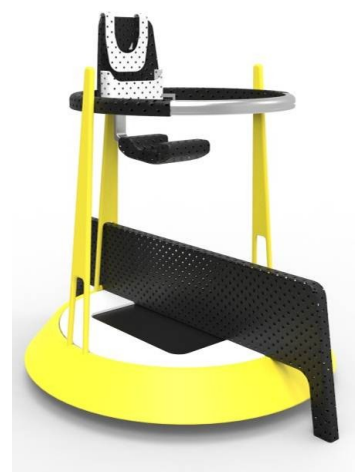

Gambar 13 Alternatif desain 2.

3. Alternatif desain 3

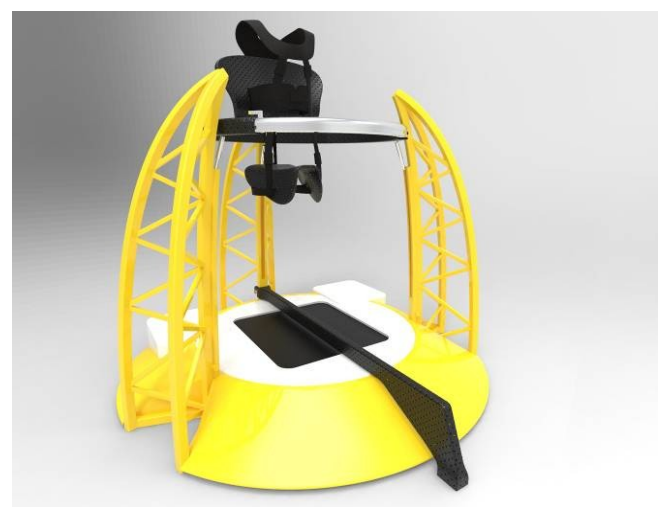

Gambar 14. Alternatif desain 3.

Alternatif desain ketiga diberi kelengkapan yang sama sesuai dengan studi dan analisis yang telah diberikan. Namun, terdapat perbedaan pada bagian tiang dengan struktur rangka yang lebih kuat serta bagian yang menempel lantai memiliki luasan yang lebih lebar jika dibandingkan alternatif yang sebelumnya sehingga permukaannya lebih landai untuk ditapaki oleh terapis maupun penderita CP.

Dari beberapa alternatif desain tersebut akan diseleksi dengan parameter berupa hasil studi dan analisis yang telah dilakukan serta kesesuain dengan kebutuhan dari pengguna sehingga terpilih desain yang paling sesuai untuk diterapkan.

\section{KESIMPULAN}

Perbandingan standar keamanan dilakukan sesuai dengan studi antropometri, studi ergonomi, data postur jalan anak serta kemampuan level GMFCS yang mereka miliki dan pendapat terapis yang telah terbiasa menggunakan produk berupa dukungan pengaman untuk anak-anak $\mathrm{CP}$. Berdasarkan data di atas, maka diperoleh standar keamanan yang paling tepat, seperti:

1. Rompi keselamatan yang terhubung dengan alat bantu jalan untuk menahan tubuh anak agar tidak jatuh ke depan serta menahan tubuh untuk mengikuti postur pada sandaran

2. Sabuk pengaman yang terhubung dengan sandaran punggung untuk menjaga postur badan agar tidak miring ke samping kanan maupun kiri

3. Sandaran punggung untuk GFMCS level III sehingga dapat membantu perbaikan postur punggung anak yang 
cenderung membungkuk

4. Abduction board untuk postur jalan yang scissor gait dengan ketinggian sesuai dengan tinggi mata kaki pada anak

5. Penggunaan orthosis sesuai dengan rekomendasi dokter pada data assessment sehingga untuk yang satu ini paling opsional jika dibandingkan dengan yang lainnya Sehingga desain yang dipilih akan memperhitungkan keamanan serta kesesuaian dengan kriteria yang telah ditentukan sebelumnya, maka dari itu terpilih desain dari alternatif dengan keterangan berupa atribut dan fitur yang dimiliki.

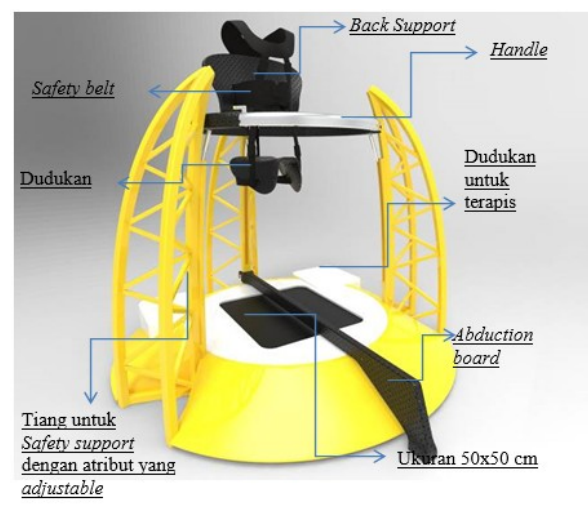

Gambar 15. Detail desain terpilih.

\section{UCAPAN TERIMA KASIH}

Penulis mengucapkan terima kasih kepada Direktorat Pendidikan Tinggi, Departemen Pendidikan dan Kebudayaan Republik Indonesia yang telah memberikan dukungan finansial melalui Beasiswa Bidik Misi tahun 2012-2016. Selain itu, terima kasih untuk para stakeholder yang telah membantu berjalannya penelitian ini, terutama untuk pihak lembaga YPCP Surabaya serta dr. Mei dan dr. Alit selaku pembimbing klinis selama penelitian di RSUD Dr. Soetomo Surabaya.

\section{DAFTAR PUSTAKA}

[1] M. Jones, E. Morgan, J. Shelton, and C. Thorogood, "Cerebral Palsy: introduction and diagnosis (part I)," J. Pediatr. Heal. Care, 2007.

[2] H. G. Chambers, "Treatment of functional limitations at the knee in ambulatory children with cerebral palsy," Eur. J. Neurol., vol. 8, no. s5, pp. 59-74, Nov. 2001.

[3] R. Palisano, P. Rosenbaum, S. Walter, D. Russell, E. Wood, and B. Galuppi, "Development and Reliability of a System to Classify Gross Motor Function in Children with Cerebral Palsy," Dev Med Child Neurol, 1997.

[4] F. Miller, Cerebral Palsy, 3rd ed. Wilmington: Springer, 1995.

[5] S. McIntyre, C. Morgan, K. Walker, and I. Novak, "Cerebral Palsydon't delay," Dev. Disabil. Res. Rev., vol. 17, no. 2, pp. 114-129, 2011.

[6] Y. Chen and A. H. HsinChen D. Fanchiang, "Effectiveness of Virtual Reality in Children With Cerebral Palsy," 2017.

[7] C. B. de M. M. Juliana Nobre de Paula, T. D. da Silva, C. M. Capelini, L. D. C. de Menezes, and S. W. \& A. H. N. R. Thais Massetti, James Tonks, "Motor performance of individuals with Cerebral Palsy in A virtual game using a mobile phone," 2017.

[8] E. Oliveira, G. Sousa, T. A. Tavares, and P. Tanner, "Sensory stimuli in gaming interaction," 2014.

[9] T. Massetti, T. D. da Silva, S. R. P. M. Denise Cardoso Ribeiro, A. H. N. Re', F. M. Favero, and C. B. de M. Monteiro., "Motor learning through Virtual Reality in cerebral," Med. Express, vol. 6, pp. 302306, 2014.

[10] C. Gagliardi et al., "Immersive Virtual Reality to improve walking abilities in Cerebral Palsy," Ann. Biomed. Eng. Soc., 2018.

[11] F. A. Rahma and D. Kuswanto, "Studi Pengaruh Desain Peralatan Postural pada Efisiensi Aktivitas dan Kestabilan Postur Pada Anak dengan Cerebral Palsy," J. Sains dan Seni ITS, vol. 6, no. 2, 2017.

[12] J. J. T. Crisco and K. Nichols, "Designing Toys and Technologies for Rehabilitation," 2015.

[13] R. C. G. F. Juliana M. de Oliveira, C. S., P. R. Pinto, S. R. Pinheiro, and V. H. C. de Albuquerque1, "Novel Virtual Environment for Alternative Treatment of Children with Cerebral Palsy," Comput. Intell. Neurosci., p. 10, 2016.

[14] F. R. C. Machado et al., "Virtual Reality Technology for Rehabilitation of Cerebral Palsy: A Literature Review," Trends Psychol., 2014.

[15] M. A. Velasco et al., BiMU -Inertial sensors and virtual reality games for the rehabilitation of the upper limb in Cerebral Palsy. Springer International Publishing AG, 2017.

[16] S. Padmakar, K. S. Kumar, and S. Parveen, "Management and Treatment for Cerebral Palsy in Children," Indian J. Pharm. Pract., vol. 11, no. 2, 2018. 